\title{
ARTICLE
}

Acute lymphoblastic leukemia

\section{Genetic predisposition to B-cell acute lymphoblastic leukemia at $14 q 11.2$ is mediated by a CEBPE promoter polymorphism}

\author{
James B. Studd $\mathbb{D}^{1} \cdot$ Minjun Yang ${ }^{2} \cdot{\text { Zhenhua } \mathrm{Li}^{3} \cdot \text { Jayaram Vijayakrishnan }}^{1} \cdot \mathrm{Yi}_{\mathrm{Lu}} \mathrm{Lu}^{3} \cdot$ Allen Eng-Juh Yeoh ${ }^{3,4} \cdot$ \\ Kajsa Paulsson $\mathbb{1}^{2} \cdot$ Richard S. Houlston $\mathbb{1}^{1,5}$
}

Received: 26 February 2018 / Revised: 21 May 2018 / Accepted: 30 May 2018 / Published online: 6 July 2018

(c) The Author(s) 2018. This article is published with open access

\begin{abstract}
Acute lymphoblastic leukaemia (ALL) is the most common paediatric malignancy. Genome-wide association studies have shown variation at $14 \mathrm{q} 11.2$ influences ALL risk. We sought to decipher causal variant(s) at $14 \mathrm{q} 11.2$ and the mechanism of tumorigenesis. We show rs2239630 G>A resides in the promoter of the CCAT enhancer-binding protein epsilon (CEBPE) gene. The rs2239630-A risk allele is associated with increased promotor activity and CEBPE expression. Depletion of $C E B P E$ in ALL cells reduces cell growth, correspondingly CEBPE binds to the promoters of electron transport and energy generation genes. RNA-seq in $C E B P E$ depleted cells demonstrates CEBPE regulates the expression of genes involved in Bcell development $(I L 7 R)$, apoptosis $(B C L 2)$, and methotrexate resistance $(R A S S 4 L)$. CEBPE regulated genes significantly overlapped in CEBPE depleted cells, ALL blasts and IGH-CEBPE translocated ALL. This suggests CEBPE regulates a similar set of genes in each, consistent with a common biological mechanism of leukemogenesis for rs2239630 associated and CEBPE translocated ALL. Finally, we map IGH-CEBPE translocation breakpoints in two cases, implicating RAG recombinase activity in their formation.
\end{abstract}

\section{Introduction}

Acute lymphoblastic leukemia (ALL) is the most common pediatric cancer in western countries. While the aetiology of

Electronic supplementary material The online version of this article (https://doi.org/10.1038/s41375-018-0184-z) contains supplementary material, which is available to authorized users.

James B. Studd

james.studd@icr.ac.uk

1 Division of Genetics and Epidemiology, The Institute of Cancer Research, London SM2 5NG, United Kingdom

2 Department of Laboratory Medicine, Division of Clinical Genetics, Lund University, 22185 Lund, Sweden

3 Centre for Translational Research in Acute Leukaemia, Department of Paediatrics, Yong Loo Lin School of Medicine, National University of Singapore, Singapore, Singapore

4 Viva-University Children's Cancer Centre, Khoo Teck PuatNational University Children's Medical Institute, National University Hospital, National University Health System, Singapore, Singapore

5 Division of Molecular Pathology, The Institute of Cancer Research, London SM2 5NG, United Kingdom
ALL is poorly understood evidence implicates initiating transforming events occuring in utero [1-3], with secondary events required for transition to malignancy [4].

Our understanding of ALL susceptibility has been transformed by genome-wide association studies (GWAS) [5-8]. GWAS have identified 11 loci associated with ALL, including the 14q11.2 risk locus, which has been replicated in multiple independent series $[9,10]$. ALL risk loci often map in the vicinity of B-cell development genes, including IKZFI, GATA3, ARID5B and at 14q11.2 mapping to CCAT enhancerbinding protein epsilon (CEBPE) [6], suggesting a central role for dysregulated B-cell development in leukemogenesis. Correspondingly, crucial B-cell development transcription factors $I K Z F 1, P A X 5$, and EBF1 are also the targets of frequent somatic mutation [11, 12], highlighting that GWAS signals and somatic mutations may impact upon the same genes.

Around $60 \%$ of BCP-ALL is characterised by translocations, most common of which, $t(12: 21)$ produces the chimeric, ETV6-RUNX1, transcription factor. Three percent of BCP-ALL features a translocation at the immunoglobulin heavy chain (IGH) locus that often involves a $C E B P$ family member. These juxtapose IGH with the coding region of $C E B P$, increasing $C E B P$ expression [13], raising the possibility that the $14 \mathrm{q} 11.2$ 
GWAS association is also mediated through increased CEBPE expression.

We sought to identify the causal polymorphism(s) for the $14 q 11.2$ association. Our data are compatible with rs2239630 in the promoter of $C E B P E$ driving the association and increasing $C E B P E$ expression.

\section{Material and methods}

\section{Ethics}

Samples and clinicopathological information were collected with ethical board approval. ALL blast RNA sequencing and genotyping sample collection was approved by the Lund University, nos 2011/289 and 2017/796. Informed consent was granted from all participants.

\section{GWAS}

UK GWAS and German GWAS have been previously reported [6, 7]. Briefly, the UK GWAS comprised 824 cases, genotyped using Illumina Human $317 \mathrm{~K}$ arrays; WTCC 2 controls were of 2699 of 1958 British Birth Cohort and 2501 from the UK Blood Service. German GWAS comprised 834 cases, genotyped using Illumina Human OmniExpress-12v1.0 arrays. Controls comprised 2024 individuals from the Heinz Nixdorf Recall study [14]. GWAS QC has been described previously [7]. Untyped genotypes were imputed using IMPUTE2 v2.3 [15] with combined UK10K (ALSPAC and TwinsUK) [16] and 1000 Genomes Project (phase III) [17] references. Poorly imputed SNPs (INFO score <0.8) were excluded. Association between SNP and ALL was performed using SNPTESTv2.5 [18]. Meta-analysis was undertaken using META v1 [18].

\section{Hi-C data analysis}

Hi-C data in Supplementary Fig.1 derived from GM12878 (MboI plus replicate) was obtained from (https://www. aidenlab.org/juicebox/) [19]. Data were viewed using balanced Knight-Ruiz normalisation at $5 \mathrm{~kb}$ resolution. HiC data in Supplementary Fig.7 (GM12878 and human embryonic stem cells) were from (http://yunliweb.its.unc. edu/HUGIn/; GSE87112).

\section{Cell lines and lentiviral transduction}

REH, NALM6, and SEM B-ALL, Jurkat T-ALL cell lines were obtained from DMSZ (Braunschweig Germany). GM12815 and GM12760 were obtained from the Coriell Institute (Camden NJ, US). Cell lines were maintained at
$37{ }^{\circ} \mathrm{C}$, with $5 \% \mathrm{CO}_{2}$ in RPMI with $10 \%$ FBS and GlutaMAX (Thermo Fisher Scientific). Doxycyclin inducible $C E B P E$ shRNA knockdown, CEBPE and ZNF148 overexpressing cell lines were generated by lentiviral transduction using CEBPE (V3THS_150517(A13), V3THS_404312 (G3)), Empty, Non-targeting pTRIPZ or pCW57.1 vectors (GE Life Sciences or from David Root Addgene plasmid \# 41393) into REH. Lentiviral particles were produced in HEK239T cells as described [20, 21]. Transduced REH cells were selected with $750 \mathrm{ng} / \mathrm{ml}$ puromycin for 1 week. Polyclonal populations were used for all assays. Cells were tested for mycoplasma using Promokine PCR Mycoplasma Test Kit I/C, no positive results were obtained. Cell identity was confirmed using Promega PowerPlex 16 microsatellite testing kit.

\section{Plasmid construction and luciferase assays}

The CEBPE promoter containing rs2239630, rs2239632 and rs2239633 and ZNF148 coding sequence cloned in pGL3 Promoter Vector (Promega) or pCW57.1 doxycycline inducible vectors, respectively. For luciferase assays, cells were electroporated and promoter activity was assayed using a Dual-Luciferase assay (Promega). Full methods are described in Supplementary material.

\section{Genotyping and sequencing}

PCR for sequencing was carried out using Thermoprime DNA polymerase (Thermo Fisher Scientific). BigDye v3.1 sequencing reactions were analysed on an ABI7900HT (Applied Biosystems) (Primers in Supplementary Table 1). The concordance between imputation of rs2239630 and 133 sequenced genotypes was $96 \%\left(R^{2}=0.90\right)$.

\section{ChIP-seq data mining, Blueprint, and Roadmap chromatin state dynamics}

B-cell epigenetic profiles were obtained from Roadmap [22] and Blueprint [23] projects and ENCODE. Chromatin state dynamics (ChomHMM) for E031 is from (http://egg2. wustl.edu/roadmap/data/byFileType/chromhmm Segmentations/ChmmModels/coreMarks/jointModel/final/) and for GM12878 from (http://hgdownload.cse.ucsc.edu/goldenPa th/hg19/encodeDCC/wgEncodeBroadHmm/ wgEncodeBroadHmmGm12878HMM.bed.gz). DNAse hypersensitivity data from the ALL blast pz294 (European Genomephenome Archive EGAD00001002499) is from (ftp://ftp. ebi.ac.uk/pub/databases/blueprint/data/homo_sapiens/GRC h38/bone_marrow/pz_294/Acute_Lymphocytic_Leukemia_ CTR/DNase-Hypersensitivity/NCMLS/) and for GM12 878 from (http://hgdownload.cse.ucsc.edu/goldenPath/ hg19/encodeDCC/wgEncodeUwDnase/ wgEncodeUwDna 
seGm12878HotspotsRep2.broadPeak.gz). Proteins binding SNP rs2239630 extracted from Encode (http://hgdownload. cse.ucsc.edu/goldenPath/hg19/encodeDCC/wgEncodeReg TfbsClustered/wgEncodeRegTfbsClusteredV3) and ChIP Atlas (http://chip-atlas.org) ChIP-seq data. REH H3K 27ac ChIP-Seq data were obtained from GSE84052 (https://www.ncbi.nlm.nih.gov/geo/query/acc.cgi?acc $=$ GS E84052).

\section{ChIP}

Cells were fixed in $1 \%$ formaldehyde in media for $10 \mathrm{~min}$ at RT with agitation and quenched in $125 \mathrm{mM}$ glycine. ChIP was performed using the Active Motif ChIP-IT Express kit (Active Motif), except after mircococcal nuclease DNA digestion, cells were sonicated in a Biorupter (Diagenode) for $10 \mathrm{~min}$ on high $30 \mathrm{~s} \mathrm{ON} / \mathrm{OFF}$ at $4{ }^{\circ} \mathrm{C}$. A total of $25 \mu \mathrm{g}$ of chromatin was incubated with $2 \mu \mathrm{g}$ of either anti-YY1 (Abcam ab12132), ELF1 (Santa Cruz sc-133096), MAX (Abcam ab53570), E2A (Santa Cruz sc133075), ZNF148 (Atlas Antibodies HPA001656), $0.5 \mu \mathrm{g}$ of SPI1 (Life Technologies A13971) or an equal amount of control antibody, mouse IgG2b (Thermo Fisher Scientific MA5-14447) or rabbit IgG (AbCam ab37415) and incubated at $4{ }^{\circ} \mathrm{C} \mathrm{O} / \mathrm{N}$ with rotation. Target quantities were interpolated and normalised to input DNA (primers in Supplementary Table 2). rs2239630 allele-specific q-RT PCR primers demonstrated a 300-fold allele preference.

\section{ChIP-sequencing}

ChIP-Seq sample preparation was performed as above, using $2 \mu \mathrm{g}$ anti-CEBPE (Atlas Antibodies HPA002928), except: (1) After final ChIP wash, DNA was eluted in $100 \mu$ l of $1 \%$ SDS and $100 \mathrm{mM} \mathrm{NaHCO}$ for $15 \mathrm{~min}$ at $\mathrm{RT}$ with rotation. (2) After the addition of $4 \mu \mathrm{l}$ of $5 \mathrm{M} \mathrm{NaCl}$ and protinase $\mathrm{K}$ digestion as per guidelines, duplicate reactions were pooled and purified using QIAquick PCR Purification columns (Qiagen). A total of $10 \mathrm{ng}$ of ChIP'd and input DNA was used as material for Illumina NGS preparation using NEBNext ChIP-Seq Library preparation kit (New England Biolabs) and sequenced on a MiSeq using 150 bp Kit v3 (Illumina). Raw FASTQ ChIP-seq reads (CEBPE and H3K27ac) were mapped to human reference genome (human_g1k_v37) using Stampy v1.0.28, for H3K27ac data common ( $>1 \%$ frequency) SNPs (dbSNP build 150) were edited to 'N'. BAM files were filtered to remove sequences with $<$ MAPQ30 score. Peaks were called using MACS2 2.1.1 [24] against input DNA. Putative CEBPE-regulated genes are listed in Supplementary Table 7 (defined as those with an Ensembl 90 TSS within 1 $\mathrm{kb}$ of a peak). CEBPE ChIP motif discovery was performed using HOMER 4.9.1 [25].

\section{siRNA transfection and reverse transcription}

A total of $4 \times 10^{6} \mathrm{REH}$ were electroporated with $200 \mathrm{nM}$ of siRNA (Eurofins Genomics) (sequences in Supplementary Table 3) as described above and incubated for $24 \mathrm{~h}$ before lysis. RNA was prepared using the Qiagen RNAeasy kit. A total of $1-2 \mu \mathrm{g}$ of RNA was reverse transcribed using MMLV (Promega) and $5 \mu \mathrm{M} \mathrm{dT}_{15}$.

\section{qRT-PCR}

qRT-PCR was performed using SYBR Green (Thermo Fisher Scientific). Samples were analysed undiluted for ChIP or 1/ 100 for cDNA. Biological replicates contained three technical replicates. PCR-quantitation, by standard curve method. Fivefold serial dilutions of DNA or cDNA were used to control for differential primer efficiency. For siRNA assays target gene expression was normalised to the geometric average of PPIA, TBP or PPIA, TUB $\beta$ as indicated.

\section{Electrophoretic mobility shift assay}

EMSAs were performed as described in ref. [26] using rs2239630 allele-specific probes (5'-AGGCTGGTGCT TCGCCCCTC[A/G]CCCTGGGCCTGAGGCTCTGC-3'). Supershift assays were performed using anti-ZNF148 (Atlas Antibodies HPA001656) or IgG isotype control (AbCam ab37415). Full methods are described in Supplementary materials.

\section{Cell growth assay}

Cell viability was quantified using a final concentration of $0.5 \mathrm{mg} / \mathrm{ml}$ MTT (3-(4,5-Dimethylthiazol-2-yl)-2,5-diphenyltetrazolium bromide, Sigma) at $37^{\circ} \mathrm{C}$ for $2 \mathrm{~h}$ and reactions stopped with an equal volume of $10 \%$ SDS with $0.01 \%$ of $37 \% \mathrm{HCl}$. Plates were incubated for $24 \mathrm{~h}$ in the dark and absorbance read at $562 \mathrm{~nm}$.

\section{Flow cytometry}

For cell cycle analysis, around $10^{6}$ cells were suspended in $500 \mu \mathrm{l}$ of $-20^{\circ} \mathrm{C} 70 \% \mathrm{v} / \mathrm{v}$ ethanol and fixed at $-20^{\circ} \mathrm{C} \mathrm{O} / \mathrm{N}$, before resuspension in $500 \mu \mathrm{lml}$ of $1 \times$ propidium iodide ( $20 \mu \mathrm{g} / \mathrm{ml}$ (Sigma), $50 \mu \mathrm{g} / \mathrm{ml}$ RNase (Sigma) in PBS) for $2 \mathrm{~h}$ at RT. Data analysis was performed in FlowJo software (Tree Star Inc.) using the Watson Pragmatic algorithm. For annexin- $\mathrm{V}$ apoptosis assays $\sim 100,000$ cells were stained in $100 \mu \mathrm{l}$ of buffer $(10 \mathrm{mM}$ HEPES, $140 \mathrm{mM} \mathrm{NaCl}, 2.5 \mathrm{mM}$ $\mathrm{CaCl}_{2}$ ) with $5 \mu \mathrm{l}$ of APC annexin-V (BD Pharmingen 550474) and $5 \mu \mathrm{l} 20 \mu \mathrm{g} / \mathrm{ml}$ DAPI (4',6-diamidino-2-phenylindole). Cells were stained for $15 \mathrm{~min}$ in the dark before the 

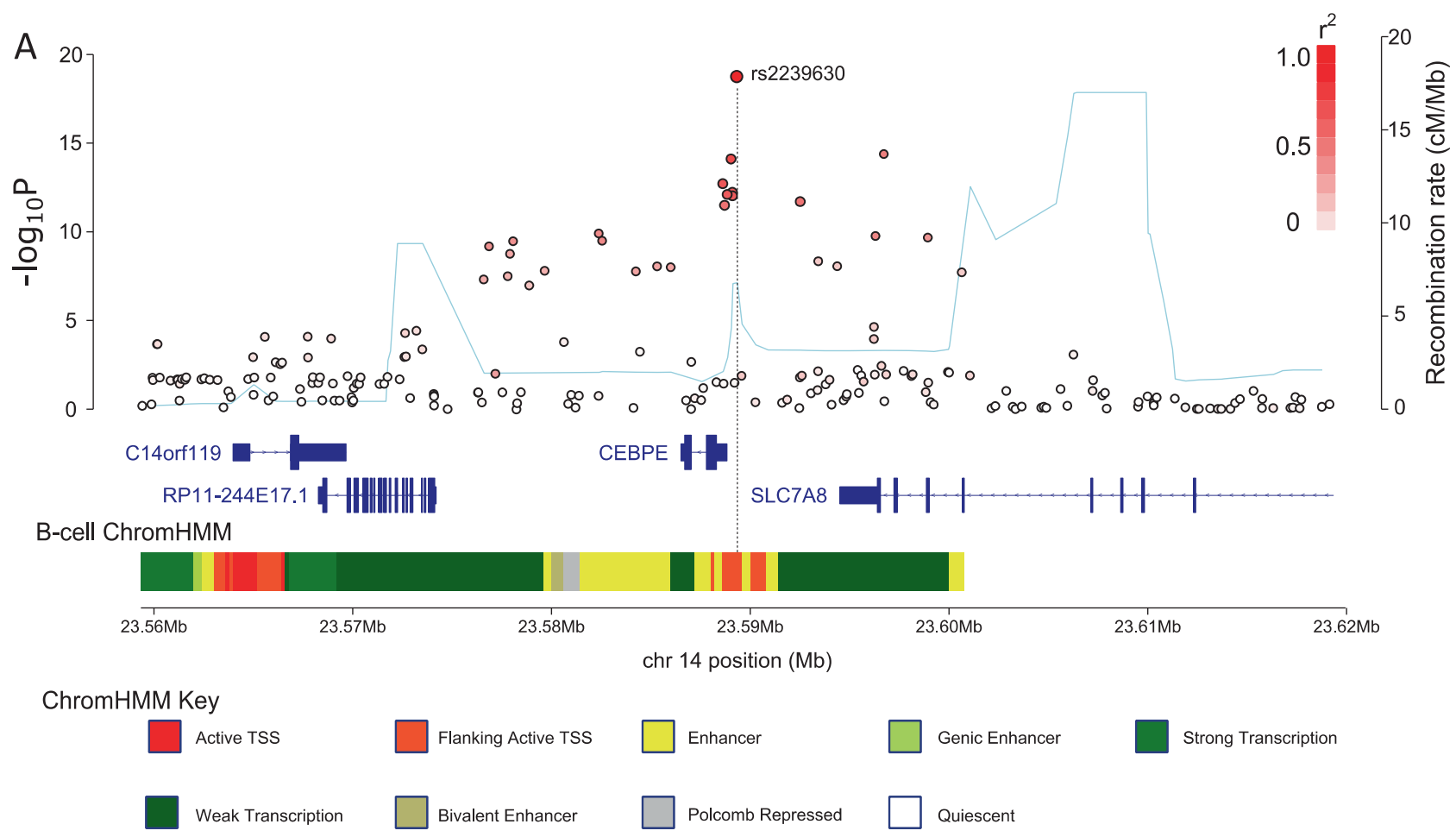

B Transcription Factor ChIP Seq
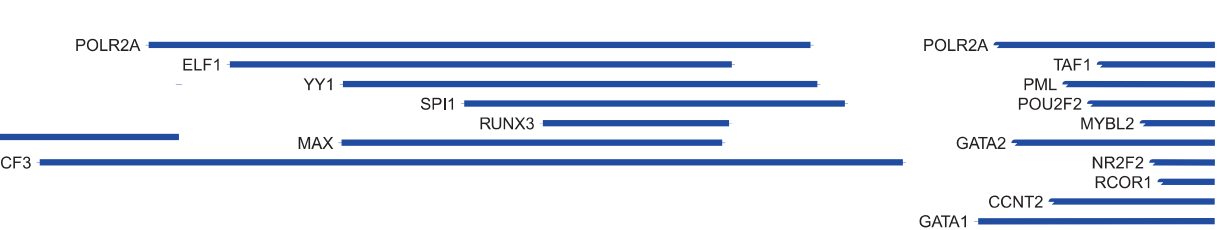

B-cell DNAse hypersensitivity
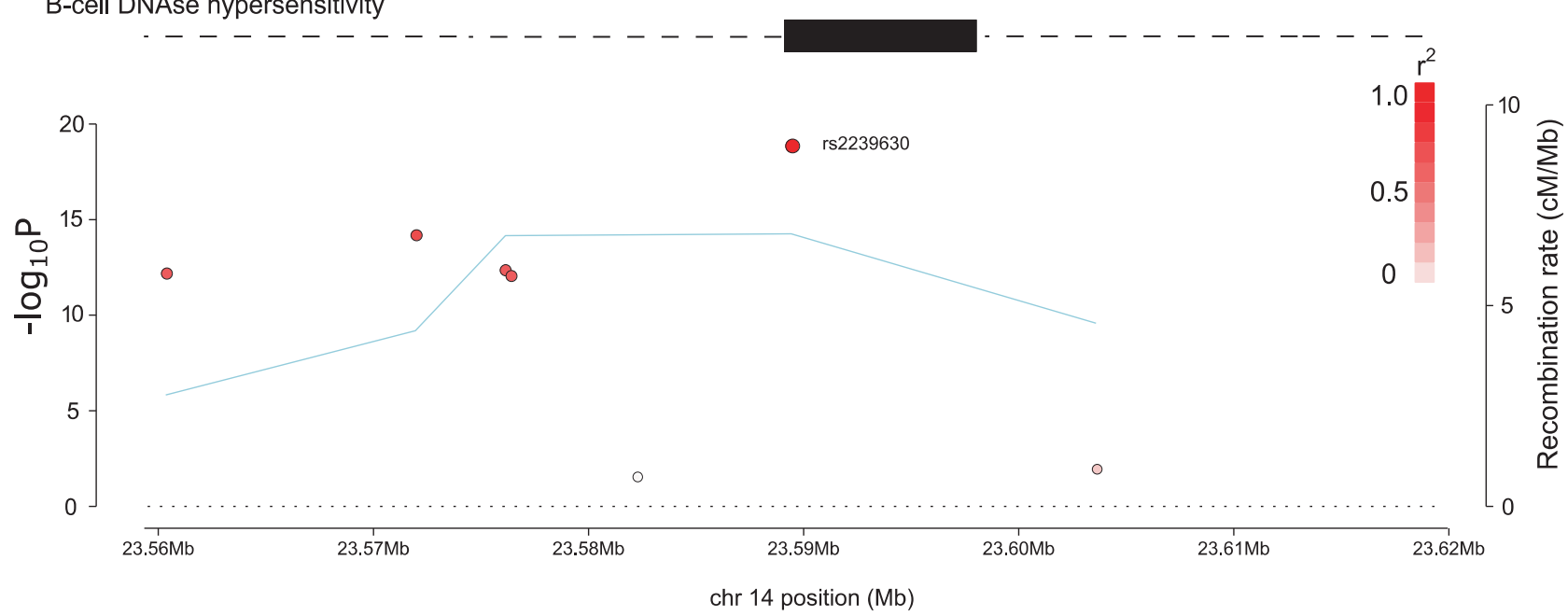

Fig. 1 Regional association plot for 14q11.2. a and b show SNPs (red circles) plotted by GWAS $P$-values $\left(-\log _{10}, y\right.$-axis) and location $(x$ axis, GRCh37/hg19). Recombination rate $(\mathrm{cM} / \mathrm{Mb})$ light blue line $(y-$ axis). SNP colour denotes linkage disequilibrium with the lead SNP, $\left(r^{2}=0\right.$, white, $r^{2}=1.0$, dark red). a Association plot annotated with genes from Gencode v27. Multicolour bar shows B-cell chromatin states from ChomHMM. b Association plot of SNPs within $1 \mathrm{~kb}$ of the lead SNP. Blue lines denote transcription factor ChIP-Seq peaks. Black bar, B-cell DNAse hypersensitivity peak 

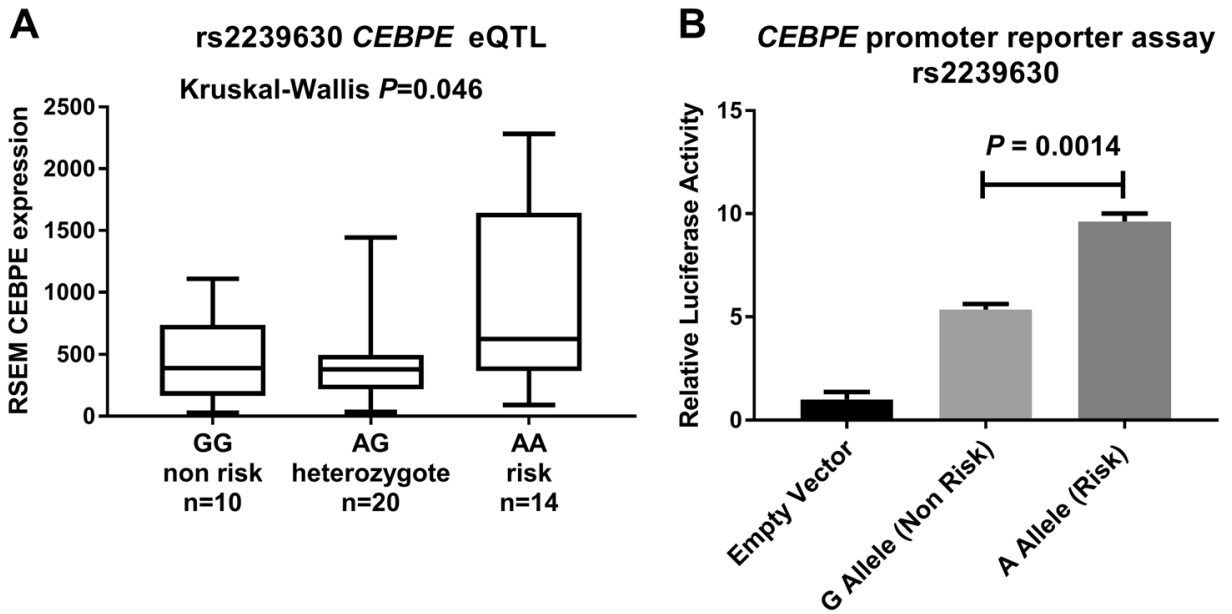

Fig. 2 rs2239630 influences $C E B P E$ expression and promoter activity. a Box (showing interquartile range and median) and whiskers (min-max) plot of CEBPE expression ( $y$-axis quantified by RSEM) by rs2239630 genotype ( $x$-axis) in B-cell ALL blasts $(n=44)$. Kruskal-Wallis $P$-value computed against all genotypes. b $C E B P E$ promoter reporter assay for alleles of rs2239630. $y$-axis shows normalised luciferase activity relative to empty vector. Data points, mean of three biological replicates \pm SEM (Student's $T$-test). Figures produced in GraphPad Prism 7 addition of $400 \mu \mathrm{l}$ of buffer, all analyses were on a LSRII cytometer (Becton Dickinson).

\section{Cell line RNA-sequencing}

shRNA expression was induced in REH cells with $1 \mu \mathrm{g} / \mathrm{ml}$ doxycycline (Sigma). Cells were lysed after $144 \mathrm{~h}$ and RNA prepared using Qiagen RNAeasy. CEBPE knockdown was verified by qRT-PCR. RNA integrity was assessed using a Tape Station 2200 (Agilent). Three biological replicates were processed each with two controls, (empty, non-targeting shRNA) and two CEBPE shRNAs (A13 and G3). Libraries were prepared using NEBNext Ultra II Directional RNA Library Prep Kit and sequenced on an Illuimna HiSeq 2500 using $2 \times 101$ version 4 paired end chemistry. RNA QC metrics are provided in Supplementary Table 4. FASTQs were filtered to remove adapter contamination using Trimmomatic v0.32 [27] and aligned to the human reference genome (human_g1k_v37) and transcript reference (GRCh37.87) using STAR v2.5.1 [28]. Gene and transcript abundance were quantified using RSEMv1.3.0 [29]. Non-coding genes and those with $<10$ mapped reads in all samples were excluded. Raw gene counts were analysed using EdgeR [30] and DeSeq2 [31].

\section{ALL blast RNA-sequencing}

IGH-CEBPE translocation BCP-ALL expression data originated from two cohorts. A total of 195 diagnostic cases [32] from Lund University analysed using TCGA RNA sequencing version 2 pipeline quantified by RSEM value and 231 diagnostic [33] cases from the National University of Singapore analysed as per 'Alignment and Bioinformatic Processing of RNA-Sequencing.'

Gene expression in 2 IGH-CEBPE cases was quantified by $Z$-score calculated from RSEM TPM (transcripts per $10^{6}$ ) based on the mean per gene expression of all non-IGHCEBPE translocated cases in each cohort.

RNA-Seq from 117 diagnostic BCP-ALL cases from TARGET was downloaded from (ftp://caftpd.nci.nih.gov/ pub/OCG-DCC/TARGET/ALL/mRNA-Seq/Phase2/L3/ expression/BCCA/). Gene expression data were converted to TPM before Spearman correlation analysis in R3.4.2 Blasts were unselected based on molecular subtype.

\section{SNP arrays}

A total of 150 BCP-ALL cases from the Lund cohort with expression data were genotyped using either Illumina Human 1M-duo Infinium BeadChip, HumanOmni1-Quad BeadChip or IlluminaOmni5M BeadChips as previously described [34, 35], and untyped SNPs imputed from the UK10K and 1000 Genomes project reference panels using the Sanger Imputation Server (https://imputation.sanger.ac.uk/).

\section{Data availability}

Raw fastq data of RNA-seq from $C E B P E$-depleted REH cells and CEBPE ChIP-seq from REH has been deposited in the European Genome Phenome archive (https://www.ebi. ac.uk/ega/home EGAS00001002877). 
Fig. 3 rs2239630 alleles differentially bind SPI1, MAX. a ChIP q-PCR of MAX and SPI1 enriched chromatin in REH cells. $x$-axis lists genomic loci of PCR primers used to amplify antibody specific (MAX or SPI1, black bars) or negative control (IgG, grey bars) ChIP samples. Raw signal normalised to input DNA (left $y$-axis). Right $y$-axis shows fold enriched (hashed bars) of antibody specific \% input vs IgG control. b Allele-specific ChIP q-PCR for MAX and SPI1 in REH
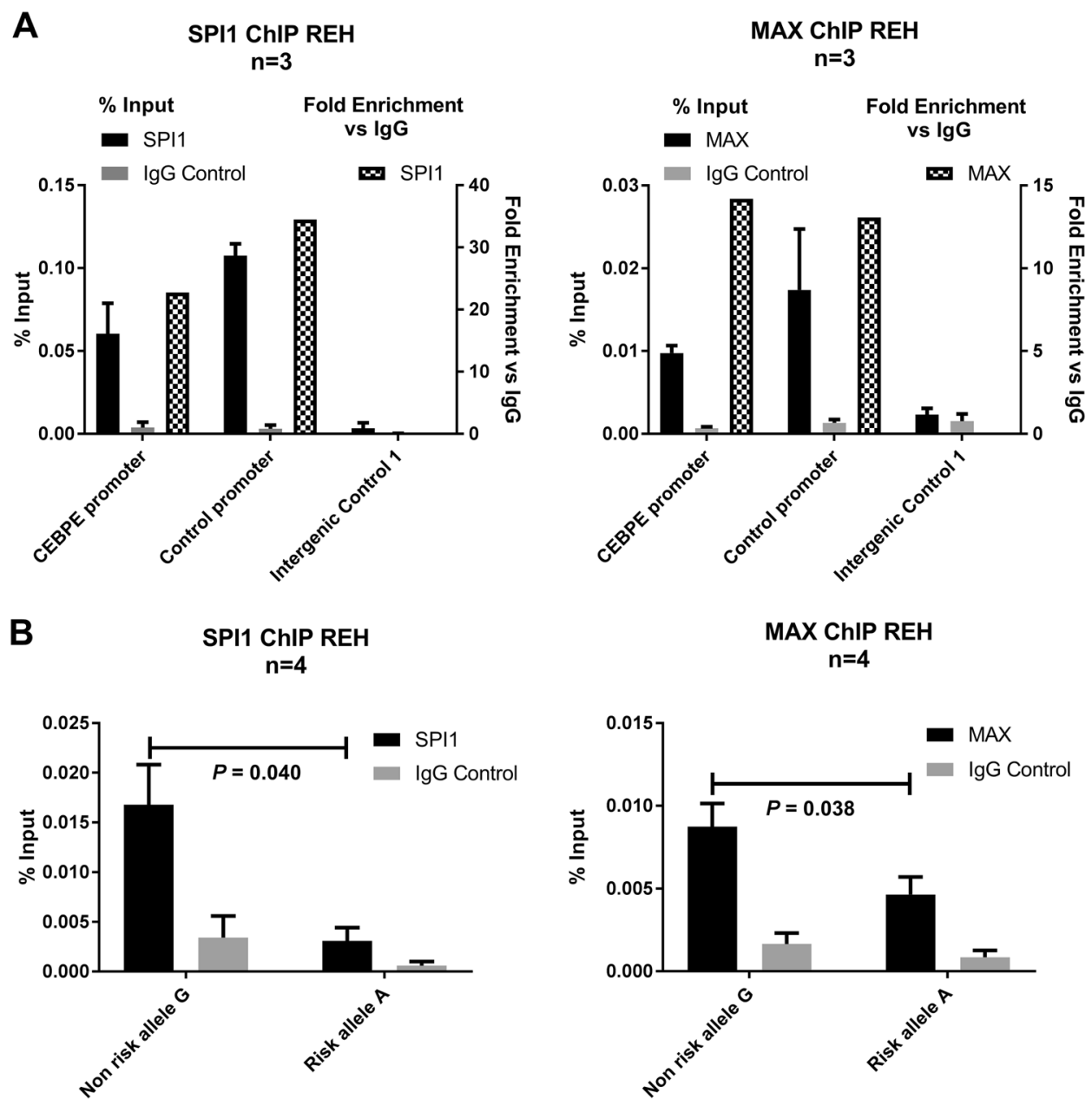

MAX ChIP REH $n=4$

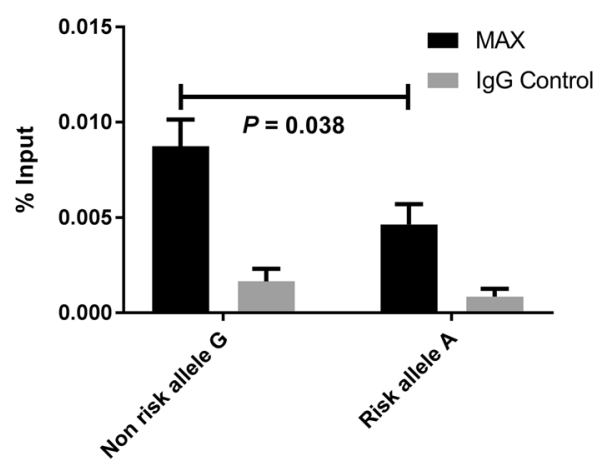

\section{Results}

\section{Epigenomic profiling of the $14 q 11.2$ locus}

We reviewed a meta-analysis of UK and German GWASs [8], fine-mapping the $14 \mathrm{q} 11.2$ risk locus by imputation. The strongest association was the imputed SNP rs2239630 $\left(P=1.66 \times 10^{-19}\right.$, odds ratio $=1.45, P_{\text {het }}=$ 0.38, Fig.1a and Supplementary Table 5). We verified imputation of rs 2230630 by sequencing 133 cases. Conditional analysis provided no evidence for an additional independent association. Referencing SNPdb.v150 confirmed imputation captured $100 \%$ of variants (minor allele frequency $[\mathrm{MAF}]>0.01)$ within the linkage disequilibrium (LD) block containing rs2239630 (pairwise $r^{2} \geq 0.4$ ).

We examined the regulatory potential of SNPs in LD with rs2239630 using chromatin state modelling [36] in primary B-cells, showing lead SNPs reside in an active promoter. Additionally, a region of B-cell DNAse hypersensitivity overlaps rs2239630 (Fig. 1a, b). Encode [37] and Chip Atlas (http://chip-atlas.org/) ChIP-Seq data also revealed binding sites for MAX, YY1, ELF1, SPI1, and TCF3 overlapping rs2239630 (Fig.1b).

\section{rs2239630 influences CEBPE expression and promoter activity}

We examined whether 14q11.2 risk SNPs influence CEBPE expression by performing expression quantitative trait loci analysis (eQTL) in ALL blast cells. Restricting our analysis to chr14 disomic blasts $(n=44)$, the rs2239630-A risk allele was associated with 1.8 -fold increased $C E B P E$ expression (Kruskal-Wallis $P=0.046$, Fig. 2a). A similar association was seen in MuTHER $(P=0.017)$ [38] and Blood $\left(P=4 \times 10^{-4}\right)$ [39] lymphoblastoid cell line datasets. To exclude the potential of a looping cis-regulatory interaction we examined GM12878 Hi-C data [19]. This revealed an interaction between the 14q11.2 locus and the promoter of SLC7A8 (Supplementary Fig.1A), however no significant association between rs2239630 genotype and SLC7A8 expression was seen in either ALL blasts $(P=$ 0.14 , Supplementary Fig.1B), MuTHER $(P=0.31)$ or blood $(P>0.05)$ eQTLs datasets. 
Fig. 4 SPI1 but not MAX regulate $C E B P E$ expression. a qRT-PCR of $S P I 1$ and $M A X$ knockdown in REH cells $(n=$ 5). b qRT-PCR of $C E B P E$ expression in SPII and MAX knockdowns $(n=5)$. All data points mean of biological replicates \pm SEM. ( $T$-test $P$ values). Target gene expression normalised to geometric mean of PPIA and TUBB relative to negative controls (mock and non-targeting siRNA) shown on $y$-axis

\section{A

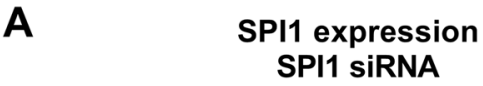

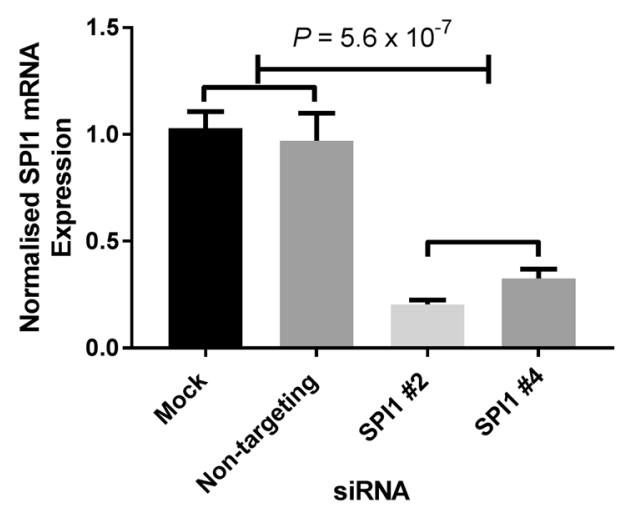
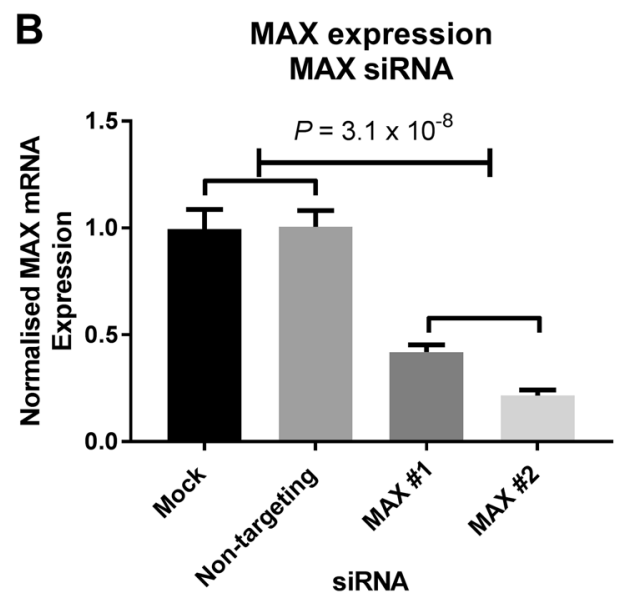

CEBPE expression SPI1 siRNA
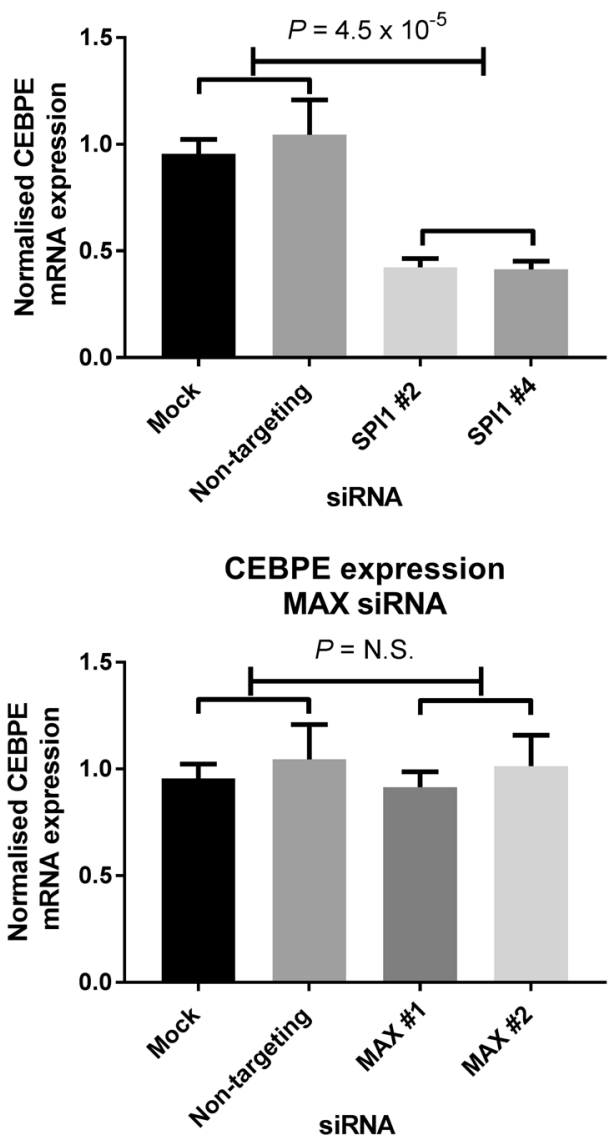

We assessed whether risk SNP genotype influences $C E B P E$ promoter activity, performing luciferase reporter assays. REH cells transfected with constructs containing the rs2239630-A risk allele displayed 1.9-fold higher luminescence ( $T$-test $P=0.0014$, Fig. $2 b$ ). The same effect was seen in additional ALL cell lines (Supplementary Fig.2). rs2239633 and rs2239632 have been reported to affect CEBPE promoter activity in non B-cell lines [40], however no relationship was shown in ALL cell lines (Supplementary Fig.2).

\section{rs2239630 alleles differentially bind SPI1 and MAX}

To examine SPI1, MAX, ELF1, YY1, and TCF3 binding at rs2239630 we performed ChIP in REH and NALM6. Only SP1 and MAX bound rs2239630 (Fig. 3a, Supplementary Fig.3A and Supplementary Fig.4). Both REH and NALM6 are heterozygous for rs2239630, allowing allele-specific qPCR to assess allelic bias of binding. MAX and SPI1 demonstrated greater affinity for rs2230630-G non-risk allele in REH ( $T$-test $P=0.040$ and $P=0.038$, Fig. $3 b$ ) and
NALM6 ( $T$-test $P=0.074$ and $P=0.074$ Supplementary Fig.3B).

\section{SPI1 regulates CEBPE expression}

We investigated whether differential SPI1 or MAX binding at rs2239630 accounts for eQTL and luciferase assays by performing siRNA knockdowns. Reduced $M A X$ expression had no impact on CEBPE. Conversely, SPII depletion resulted in decreased $C E B P E$ (Fig. 4a, b), a finding inconsistent with rs2239630-A increasing CEBPE expression.

\section{ZNF148 binds the risk allele of rs2239630 and inhibits expression of CEBPE}

To search for additional allele-specific protein binding at rs2239630 we performed electrophoretic mobility shift assays (EMSA). Greater protein or complex binding was shown for the rs2239630-A allele in REH, SEM, and JURKAT (Fig. 5a and Supplementary Fig.5). We used HaploReg v4.1 [41], RegulomeDB [42], and MotifBreakR [43] to identify motifs 

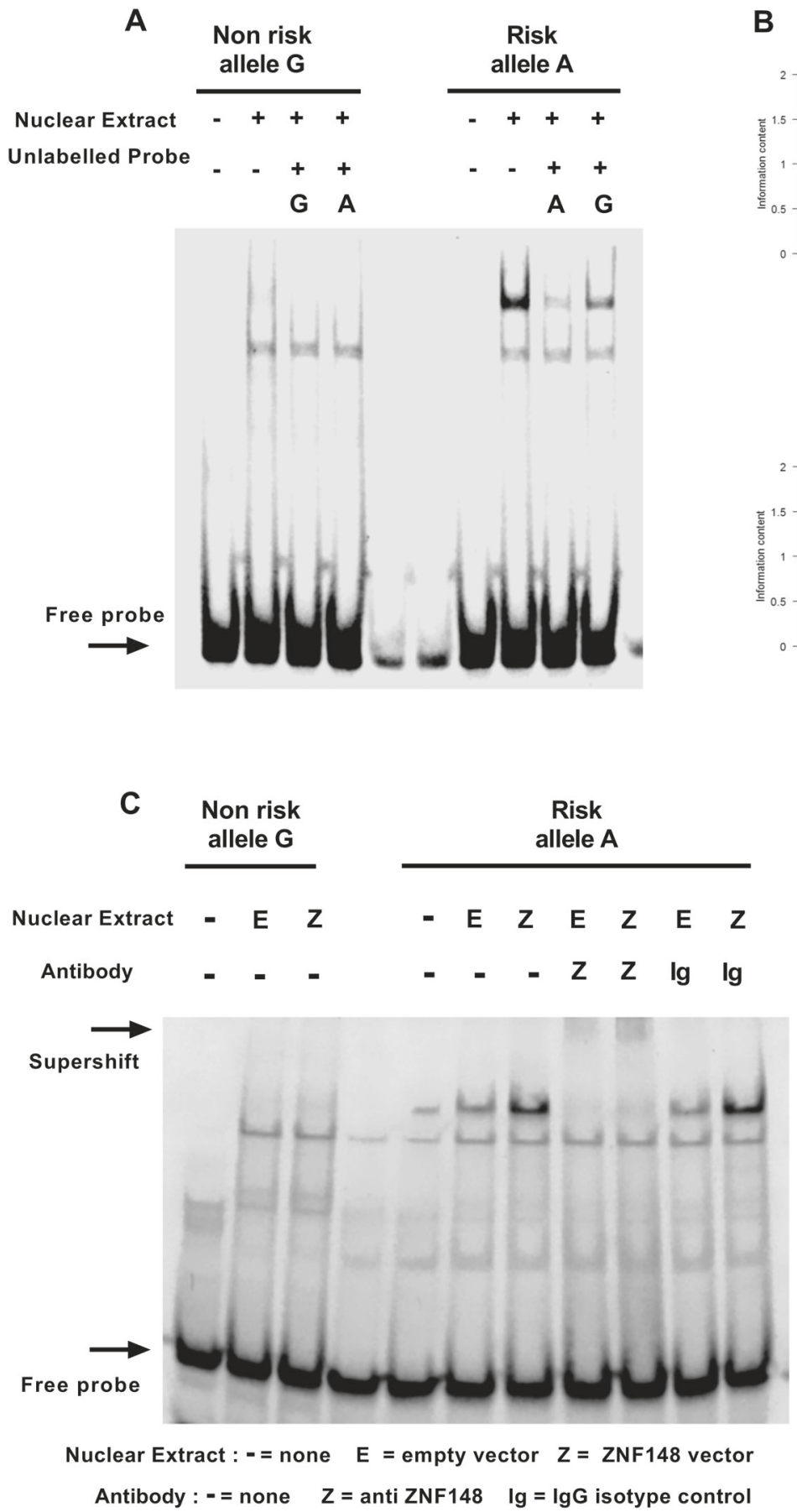

Fig. 5 ZNF148 binds the rs 2239630 risk allele. a EMSA allele-specific probes for rs 2239630 incubated with REH nuclear protein. b Position weighted matrices for ZNF589 and ZNF148 with corresponding genomic sequence below. Yellow boxes highlight base mismatches.

disrupted by rs 2239630 (Fig. 5b). Using the criteria of preferential affinity for rs2239630-A allele, a predicted strong effect and expression in REH, identified ZNF148 and ZNF589 (Supplementary Table 6). Two mismatches within the motif of ZNF589 overlapping rs2239630 (Fig. 5b) suggested ZNF148 as the most credible candidate. Performing
B
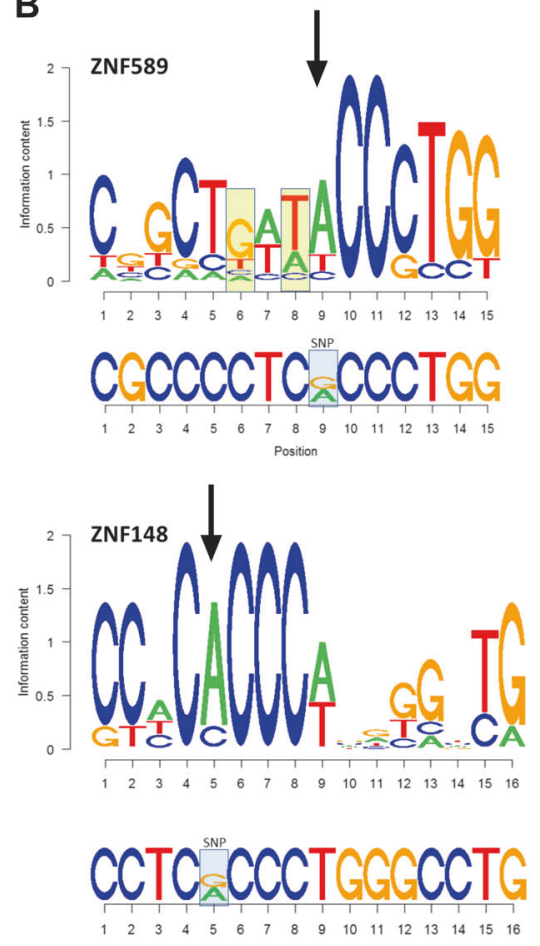

Position

c EMSA in REH showing differential allelic binding is caused by ZNF148. Supershift assay performed by addition of anti-ZNF148 antibody or IgG isotype control

EMSA antibody supershift assays with REH nuclear extract overexpressing ZNF148 identified ZNF148 as the protein preferentially bound to rs2239630-A (Fig. 5c). Allele-specific binding of ZNF148 was confirmed by ChIP-qPCR (Fig. 6a, b). To investigate allele-specific binding of ZNF148 on $C E B P E$ we generated inducible ZNF148-overexpressing REH 
Fig. 6 ZNF148 binds the rs2239630 risk allele and represses CEBPE. a ZNF148 ChIP q-PCR in REH cells. Left $x$-axis raw signal normalised to input DNA, right $y$-axis, fold enrichment (hashed bars) vs IgG control. b Allele-specific ChIP q-PCR for ZNF148 in REH. $\mathbf{c}$ qRT PCR for ZNF148 and $C E B P E$ mRNA expression in ZNF148-overexpressing REH. T-test $P$-values. Target gene expression normalised to geometric mean of PPIA and TUBB, shown relative to empty vector control. Data points, mean of biological replicates \pm SEM. (d) H3K27ac ChIP-seq in REH. Reads mapping to each allele lead SNPs in the 14q11.2 risk loci are enumerated on the $y$-axis, hashed bars show the enrichment for reads mapping to risk alleles. * binomial $P$-values $<0.05$
A
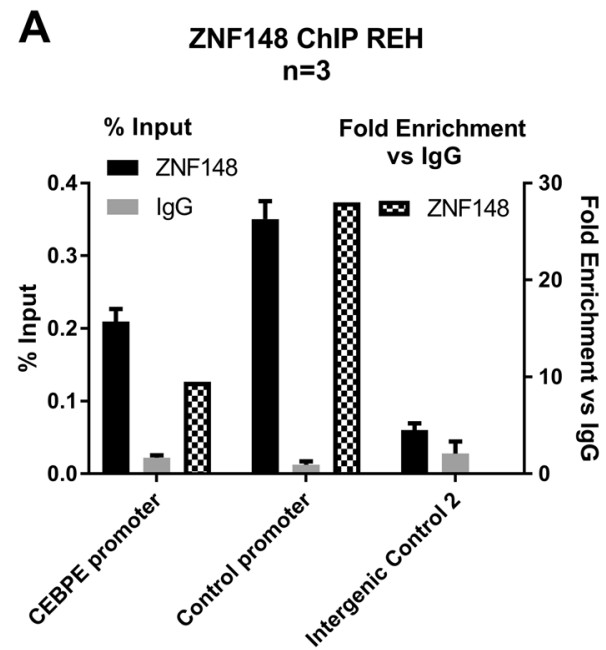

B
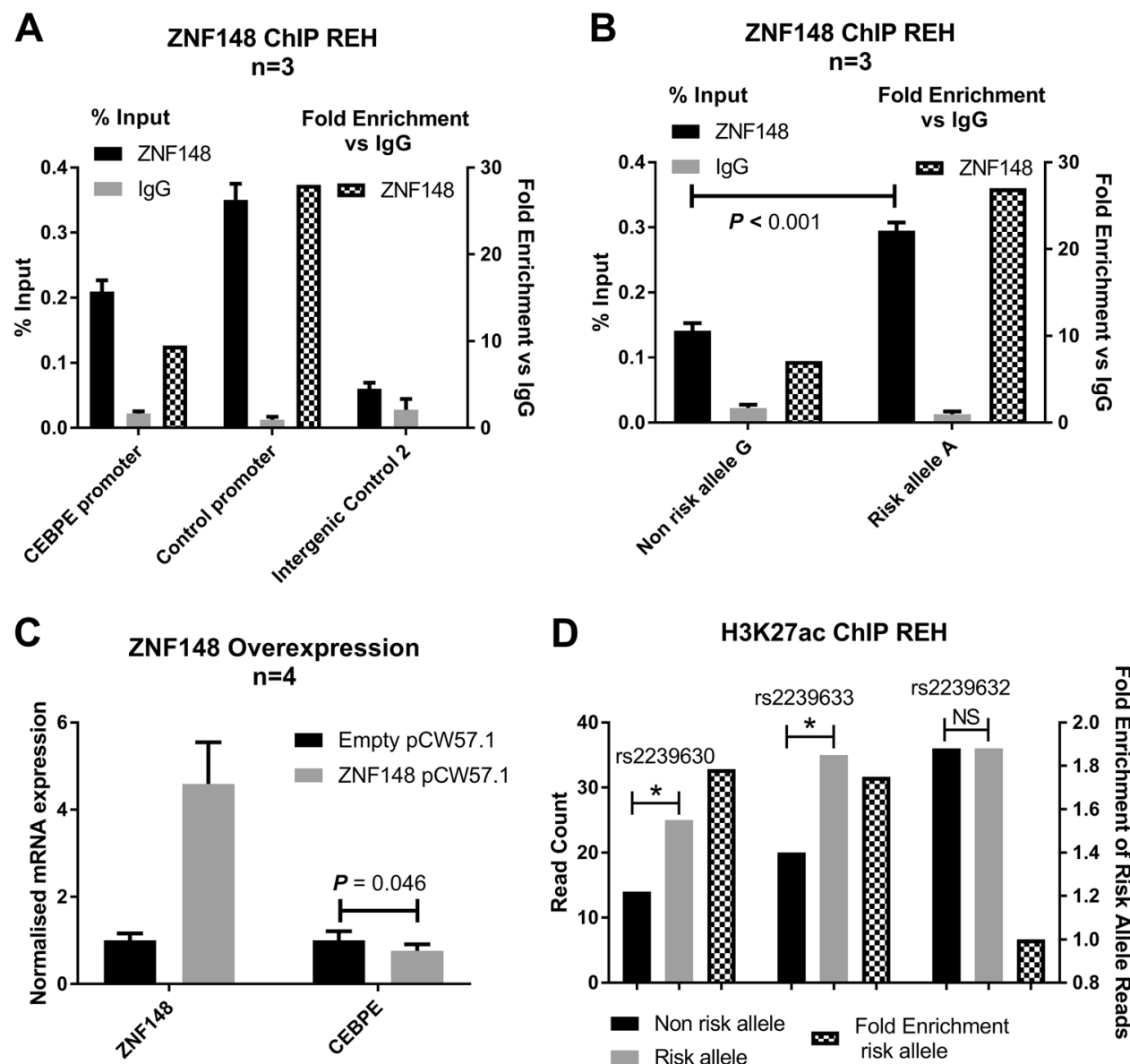

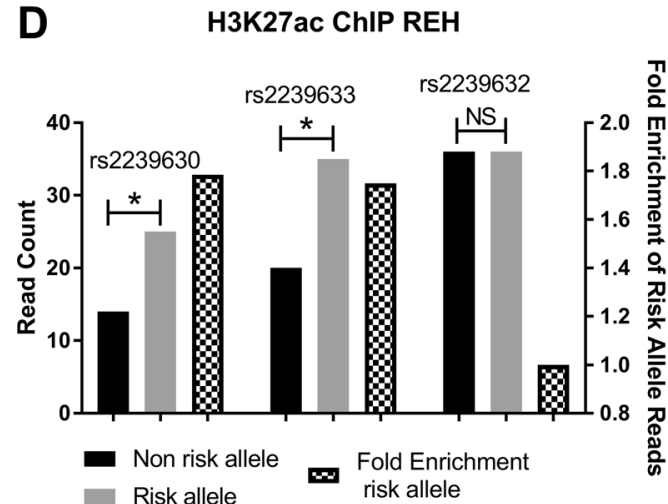

cells. Overexpression of $Z N F 148$ reduced $C E B P E$ expression (T-test $P=0.046$, Fig. 6c).

\section{rs2239630-A is associated with marks of active transcription}

Since effects of SPI1 and ZNF148 interaction at rs2239630 were inconsistent with higher risk allele $C E B P E$ expression we sought evidence of allele-specific expression (ASE). As it is not possible to directly measure ASE of $C E B P E$, in the absence of a proxy coding SNP for rs2239630, we assayed CEBPE promoter H3K27 acetylation. REH H3K27ac ChIPseq showed significantly higher reads counts mapping to the rs2239630-A risk allele (binomial $P=0.027$, Fig. 6d), no bias was present in input DNA (binomial $P=0.99$ ). Moreover the risk allele bias was higher for rs2239630 than either rs2239632 or rs2239633. These data are consistent with increased transcriptional activity due to allele-specific promoter acetylation.

\section{Functional and transcriptional profiling of CEBPE}

To investigate CEBPE function in ALL we generated doxycycline inducible CEBPE shRNA cell lines, in REH.
CEBPE knockdown reduced cell growth (Fig. 7a), but did not affect cell cycle or apoptosis (Supplementary Fig.6A). $C E B P E$-depleted cells did not show differential apoptosis either alone or in combination with cisplatin or TNF $\alpha$ (Supplementary Fig.6B-D).

To identify genes and pathways regulated by CEBPE, we performed ChIP-Seq and RNA-Seq in CEBPEdepleted cells. Peak calling of ChIP-Seq data identified 313 enriched loci, 83 mapping within $1 \mathrm{~kb}$ of a transcription start site (TSS) (Supplementary Table 7). We identified enriched motifs using HOMER 4.9.1, revealing the CEBPE consensus motif as TTGCGCAA $\left(P=1 \times 10^{-150}\right)$ (Supplementary Table 8). Protein-coding genes showing the highest promoter enrichment were GAS7, SPRY4, ANKRD13D, TFEB, and ADGB. Pathways enriched for putative CEBPE-regulated genes were interrogated using REACTOME [44] and PANTHER [45]. Analyses were consistent with CEBPE binding sites being enriched in the promoters of genes involved in precursor metabolites and energy biogenesis $\left(P_{\mathrm{REACTOME}}=5.8 \times 10^{-3}\right.$, $\left.P_{\text {Panther }}=4.2 \times 10^{-3}\right)$ and respiration/electron transport $\left(P_{\text {REACTOME }}=0.01, P_{\text {Panther }}=0.067\right)$, which may contribute to reduced metabolic activity and growth of $C E B P E$ depleted cells. 


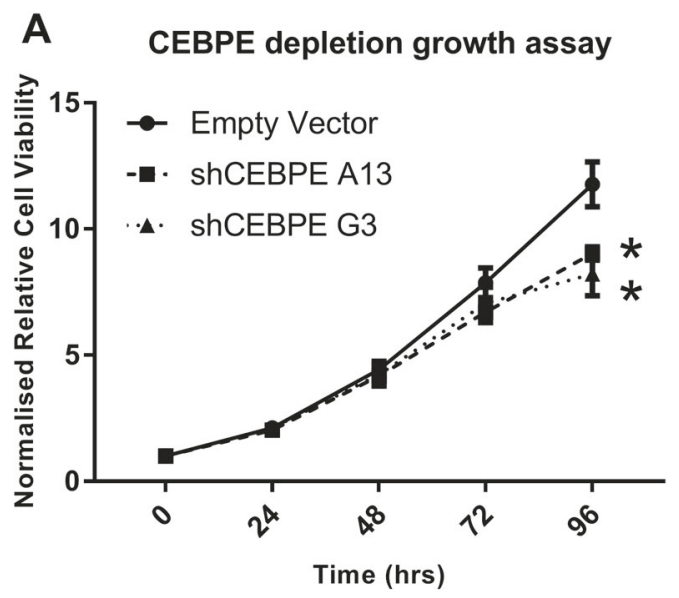

B Singapore IGH/CEBPE

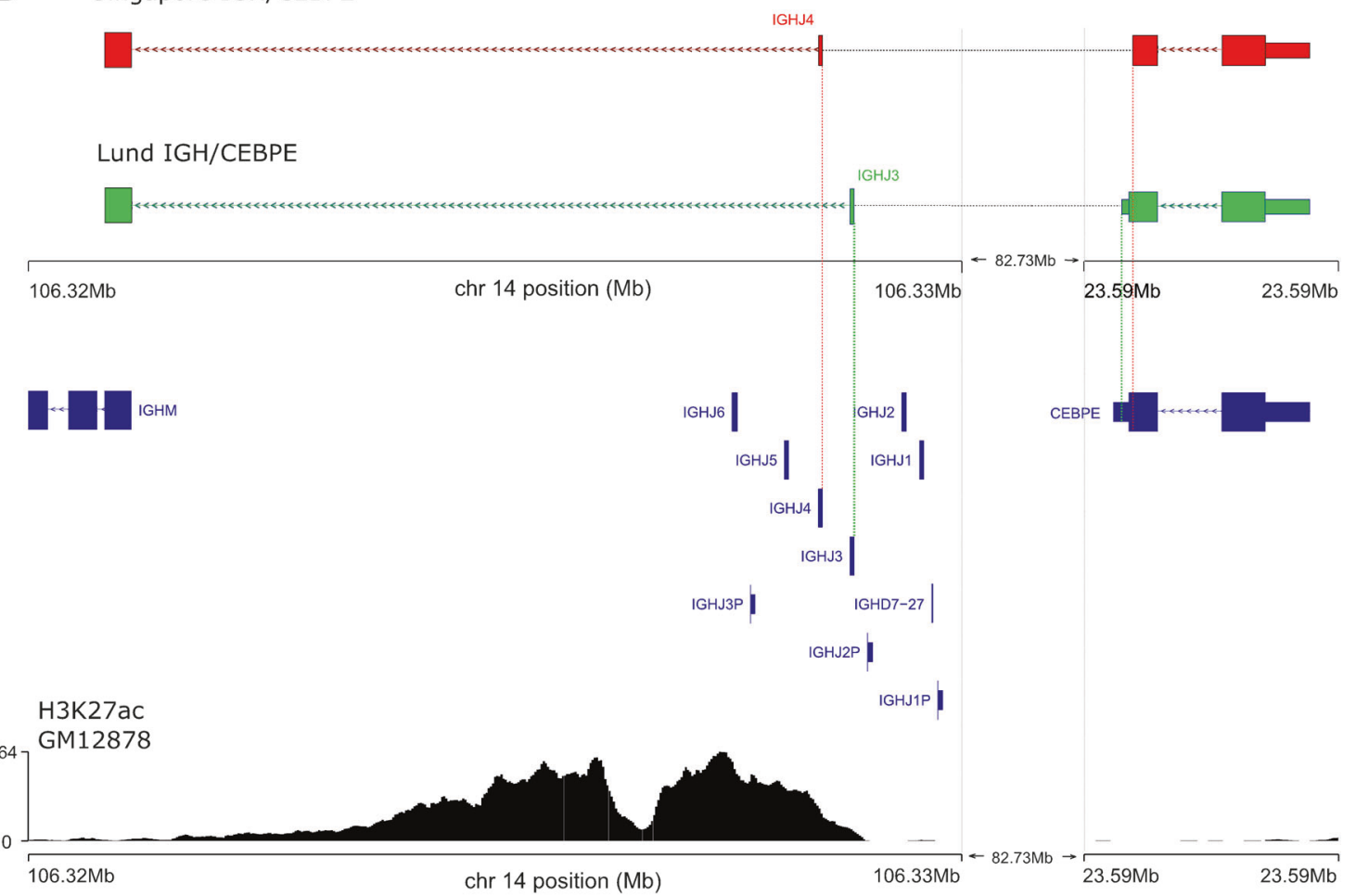

Fig. 7 CEBPE depletion reduces cell growth. Genomic breakpoints in two IGH-CEBPE ALL cases. a Cell viability/growth assay in CEBPEdepleted cells. Absorbance $(562 \mathrm{~nm})$ normalised to $0 \mathrm{~h}$ matched shRNA control shown on $y$-axis. $* T$-test $P$-value $<0.05$. Data points, mean of four biological replicates \pm SEM. b Schematic of IGH-

We identified genes regulated by $C E B P E$ by performing RNA-Seq in CEBPE-depleted cells (Supplementary Table 9). Consistent with a role in granulocyte development, CEBPE positively regulated $M P O$ and $P L D 1$, genes of B-cell relevance included IL7R, PRAME, BCL2, and $R A S S F 4$, each positively regulated. To identify differentially expressed genes directly regulated by $C E B P E$ we mapped ChIP-Seq peaks and gene TSS using Hi-C data in lymphoblastoid and embryonic stem cells [46]. Findings were consistent with direct regulation for 13 of 73 top
CEBPE translocation breakpoints. Upper panel, RNA and Sanger sequencing reads spanning $\sim 83 \mathrm{Mb}$ between breakpoints, denoted by dashed lines. Case-specific breakpoints are denoted by coloured vertical lines. Lower panel, genes mapping to the region and GM12878 H3K27ac ChIP-seq

differentially expressed genes. Hi-C contacts between ChIPSeq peaks and TSS were seen for 10 of 73 genes, including $B C L 2, M P O$, and FAM69C (Supplementary Table 9). The resolution of Hi-C and proximity of UGT3A2 and $\mathrm{CDH} 12$ TSS with ChIP-Seq peaks precluded demonstration of an interaction. Finally, the promoter of C4orf32 bound CEBPE directly.

To evaluate the similarity of $C E B P E$-regulated genes in $C E B P E$-depleted and BCP-ALL blast cells we examined RNA-Seq from 117 diagnostic cases from TARGET [47]. 
First, we identified $C E B P E$-correlated genes, restricting our analysis to those correlated at $P<5 \times 10^{-4}$, a significant enrichment in differentially expressed genes from $C E B P E$ depleted cells was seen (binomial $P=5.4 \times 10^{-4}$ ). We next examined the similarity of $C E B P E$-correlated gene profiles from two IGH-CEBPE translocated BCP-ALL cases and 117 ALL blasts. CEBPE was highly over-expressed in IGHCEBPE translocated cases (mean $Z$-score $=4.6$ ) and the top 150 differentially expressed genes were highly enriched for $C E B P E$-correlated genes in the 117 BCP-ALL cases (Binomial $P=2.9 \times 10^{-7}$ ).

\section{Mapping IGH-CEBPE breakpoints}

To explore the integrity of the $C E B P E$ transcript associated with $\mathrm{t}(14: 14)$ IGH-CEBPE ALL, we mapped chr14 breakpoints by RNA and Sanger sequencing of genomic DNA. In contrast to the breakpoints in one previously reported IGHCEBPE case [13] we observed breakpoints in the $3^{\prime}$ of $C E B P E$ and the $5^{\prime}$ of IGHJ transcripts in both cases (Fig. 7b and Supplementary Figure 7 and 8). Although in one case breakpoints truncated the terminal 13 amino acids of $C E B P E$ this affected a region of no known function suggesting no functional impact, and in a second case the coding sequence was unaffected.

The locus upstream of IGHJ breakpoints contains extensive H3K27ac, associated with enhancer activity, consistent with this region driving increased CEBPE expression (Fig. 7). The position breakpoints at IGHJ implicate aberrant RAG1 and/or RAG2 somatic VDJ recombination in their formation [48]. However, examination downstream of CEBPE breakpoints revealed only consensus RAG hexamer sequence, and not the nonamer sequence required for canonical RAG activity.

\section{Discussion}

Our data provide a plausible mechanism of increased ALL risk at $14 \mathrm{q} 11.2$, driven by increased $C E B P E$ expression mediated via the rs2239630-A risk allele. Epigenetic, eQTL and luciferase data suggest differential promoter activity conferred by rs 2239630 results in allele-specific expression of $C E B P E$.

We identified allele-specific interaction of SPI1 and ZNF148 at rs2239630. The regulatory impact of which is to attenuate increased $C E B P E$ expression associated with rs2239630-A. This suggests that modulation of expression due to allele-specific binding of transcription factors is complex and the aggregate of multiple interacting proteins.

Previously, Wiemels et al. [49] proposed rs2239635 as the 14q11 functional variant for ALL. rs2239635, is weakly correlated with rs2239630 $\left(r^{2}=0.52\right)$ mapping to the $5^{\prime}$ -
UTR of CEBPE (Supplementary Figure 9). In contrast to rs2239630, neither GTEx v7, Blood [39] nor MuTHER [38] datasets showed a relationship between rs2239635 genotype and $C E B P E$ expression and RNA-Seq data in chr14 disomic ALL blasts heterozygous for rs 2239635 showed no allele bias $(P=0.92, n=20)$. The authors proposed IKZF1 binding at rs2239635 based on low ChIP enrichment $(<2-$ fold) in bone marrow, which contains a low proportion of B-cell lineages. An analysis of eight B-cell ChIP-Seq datasets in five B-cell types, including precursors, showed no evidence of IKZF1 binding rs2239635 [50-53]. Additionally in silico data, cited by the authors, predicts only a minimal impact of rs2239635 on IKZF1 binding despite apparent abolition of risk allele occupancy (Supplementary Table 10). Furthermore, data from ENCODE suggest rs2239635 is unbound by transcription factors and possesses reduced marks of active transcription relative to rs2239630.

$C E B P E$ is a member of the CEBP transcription factor family primarily expressed during granulocyte differentiation. Homozygous mutations in CEBPE cause congenitalspecific granule deficiency [54] and mice with CEBPE disruption have myelopoietic defects [55]. However BCPALL featuring IGH translocations involving CEBP genes establishes their role in B-cell oncogenesis [13].

We have shown $C E B P E$ depletion reduces growth in ALL cells. Transcriptional profiling of CEBPE-depleted cells demonstrates that it regulates the expression of genes with a role in B-cell development (IL7R [56]), apoptosis inhibition (BCL2 [57]), methotrexate resistance (RASSF4 [58]) and cell survival (PRAME [59]), identifying potential mediators of disease development.

IL7 signalling is required for adult bone marrow B-cell production, where it increases B-cell differentiation, proliferation, and survival [60]. Correspondingly, IL7R-/mice do not respond to IL7 and have severely reduced Band T-cell counts [61]; whereas, transgenic IL7overexpressing mice develop lymphoproliferative disorders of B- and T-cell compartments [62].

BCL2 (B-cell lymphoma 2) expression is elevated in many tumours, including ALL [63, 64], and has been associated with an adverse prognosis. Correspondingly, BCL2 inhibition induces apoptosis in a number of ALL cell lines [57], but not REH, this response has been associated with serine 70 phosphorylation of BCL2 [65], a mark lacking in these cells [66]. BCL2 is currently under investigation as a target for therapy [67].

PRAME (preferentially expressed antigen in melanoma) expression is elevated in ALL [68] and other malignancies [59]. PRAME antagonises retinoic acid signalling promoting cell survival [69]. It encodes an antigen recognised by autologous cytolytic $\mathrm{T}$ lymphocytes and has been suggested as a target for immunotherapy. 
Inherited variation and expression of RASSF4 are associated with accumulation of methotrexate polyglutamates [58]. Methotrexate is one of the main components of ALL treatment and conversion of the pro-drug to a polyglutamated form is required for efficacy.

Taken together this suggests CEBPE influences the expression of genes potentially contributing to various stages of disease development and progression.

Comparing the expression profiles of $C E B P E$-depleted cells to BCP-ALL blasts we find $C E B P E$ expression affects similar transcriptional programs in both. We also compare $C E B P E$-regulated genes in two cases with IGH-CEBPE translocation with BCP-ALL blasts, again demonstrating significant similarities suggesting that the mechanism by which CEBPE drives leukemogenesis is the same for $14 \mathrm{q} 11.2$ associated and translocated ALL.

In conclusion, we have shown increased $C E B P E$ expression in ALL patients carrying the rs2239630-A risk allele, and identified genes, involved in B-cell development and apoptosis, via which $C E B P E$ may influence the risk of disease, thus providing a mechanistic basis for the $14 \mathrm{q} 11.2$ risk association for ALL. Further functional studies, however, are required to fully decipher the biological basis of differential $C E P B E$ expression on ALL oncogenesis.

Author contributions J.B.S. and R.S.H. designed the study and drafted the manuscript; J.B.S. and Y.L. performed laboratory analyses; J.B.S., M.Y., Z.L., and K.P. performed bioinformatic and statistical analyses.

\section{Compliance with ethical standards}

Conflict of interest The authors declare that they have no conflict of interest.

Open Access This article is licensed under a Creative Commons Attribution 4.0 International License, which permits use, sharing, adaptation, distribution and reproduction in any medium or format, as long as you give appropriate credit to the original author(s) and the source, provide a link to the Creative Commons license, and indicate if changes were made. The images or other third party material in this article are included in the article's Creative Commons license, unless indicated otherwise in a credit line to the material. If material is not included in the article's Creative Commons license and your intended use is not permitted by statutory regulation or exceeds the permitted use, you will need to obtain permission directly from the copyright holder. To view a copy of this license, visit http://creativecommons. org/licenses/by/4.0/.

\section{References}

1. Renate Panzer-Grümayer E, Fasching K, Panzer S, Hettinger K, Schmitt K, Stöckler-lpsiroglu S, et al. Nondisjunction of chromosomes leading to hyperdiploid childhood B-cell precursor acute lymphoblastic leukemia is an early event during leukemogenesis. Blood. 2002;100:347-9.

2. Gruhn B, Taub JW, Ge Y, Beck JF, Zell R, Häfer R, et al. Prenatal origin of childhood acute lymphoblastic leukemia, association with birth weight and hyperdiploidy. Leukemia. 2008;22:1692-7.
3. Maia AT, van der Velden VHJ, Harrison CJ, Szczepanski T, Williams MD, Griffiths MJ, et al. Prenatal origin of hyperdiploid acute lymphoblastic leukemia in identical twins. Leukemia. 2003;17:2202-6.

4. Mori H, Colman SM, Xiao Z, Ford AM, Healy LE, Donaldson C, et al. Chromosome translocations and covert leukemic clones are generated during normal fetal development. Proc Natl Acad Sci USA. 2002;99:8242-7.

5. Treviño LR, Yang W, French D, Hunger SP, Carroll WL, Devidas $\mathrm{M}$, et al. Germline genomic variants associated with childhood acute lymphoblastic leukemia. Nat Genet. 2009;41:1001-5.

6. Papaemmanuil E, Hosking FJ, Vijayakrishnan J, Price A, Olver B, Sheridan E, et al. Loci on 7p12.2, 10q21.2 and 14q11.2 are associated with risk of childhood acute lymphoblastic leukemia. Nat Genet. 2009;41:1006-10.

7. Migliorini G, Fiege B, Hosking FJ, Ma Y, Kumar R, Sherborne $\mathrm{AL}$, et al. Variation at $10 \mathrm{p} 12.2$ and $10 \mathrm{p} 14$ influences risk of childhood B-cell acute lymphoblastic leukemia and phenotype. Blood. 2013;122:3298-307.

8. Vijayakrishnan J, Kumar R, Henrion MYR, Moorman AV, Rachakonda PS, Hosen I, et al. A genome-wide association study identifies risk loci for childhood acute lymphoblastic leukemia at 10q26.13 and 12q23.1. Leukemia. 2017;31:573-9.

9. Prasad RB, Hosking FJ, Vijayakrishnan J, Papaemmanuil E, Koehler R, Greaves M, et al. Verification of the susceptibility loci on $7 \mathrm{p} 12.2,10 \mathrm{q} 21.2$, and $14 \mathrm{q} 11.2$ in precursor B-cell acute lymphoblastic leukemia of childhood. Blood. 2010;115: 1765-7.

10. Hsu LI, Chokkalingam AP, Briggs FBS, Walsh K, Crouse V, Fu C, et al. Association of genetic variation in IKZF1, ARID5B, and CEBPE and surrogates for early-life infections with the risk of acute lymphoblastic leukemia in Hispanic children. Cancer Causes Control. 2015;26:609-19.

11. Mullighan CG, Goorha S, Radtke I, Miller CB, Coustan-Smith E, Dalton JD, et al. Genome-wide analysis of genetic alterations in acute lymphoblastic leukaemia. Nature. 2007;446:758-64.

12. Schwab CJ, Chilton L, Morrison H, Jones L, Al-Shehhi H, Erhorn A, et al. Genes commonly deleted in childhood B-cell precursor acute lymphoblastic leukemia: association with cytogenetics and clinical features. Haematolica. 2013;98:1081-8.

13. Akasaka T, Balasas T, Russel LJ, Sugimoto KJ, Majid A, Walewska R, et al. Five members of the CEBP transcription factor family are targeted by recurrent IGH translocations in B-cell precursor acute lymphoblastic leukemia (BCP-ALL). Blood. 2007;109:3451-61.

14. Kröger K, Stang A, Kondratieva J, Moebus S, Beck E, Schmermund A, et al. Prevalence of peripheral arterial disease - Results of the Heinz Nixdorf Recall Study. Eur J Epidemiol. 2006;21:279-85.

15. Howie BN, Donnelly P, Marchini J. A flexible and accurate genotype imputation method for the next generation of genomewide association studies. PLoS Genet. 2009;5:e1000529.

16. Walter K, Min JL, Huang J, Crooks L, Memari Y, McCarthy S, et al. The UK10K project identifies rare variants in health and disease. Nature. 2015;526:82-90.

17. Auton A, Abecasis GR, Altshuler DM, Durbin RM, Abecasis GR, Bentley DR, et al. A global reference for human genetic variation. Nature. 2015;526:68-74.

18. Marchini J, Howie B, Myers S, McVean G, Donnelly P. A new multipoint method for genome-wide association studies by imputation of genotypes. Nature. 2007;39:906-13.

19. Rao SSP, Huntley MH, Durand NC, Stamenova EK, Bochkov ID, Robinson JT, et al. A 3D map of the human genome at kilobase resolution reveals principles of chromatin looping. Cell. 2014;159:1665-80. 
20. Wiznerowicz M, Trono D. Conditional suppression of cellular genes: lentivirus vector-mediated drug-inducible RNA interference. J Virol. 2003;77:8957-61.

21. Zufferey R, Nagy D, Mandel RJ, Naldini L, Trono D. Multiply attenuated lentiviral vector achieves efficient gene delivery in vivo. Nature. 1997;15:871-5.

22. Bernstein BE, Stamatoyannopoulos JA, Costello JF, Ren B, Milosavljevic A, Meissner A, et al. The NIH roadmap epigenomics mapping consortium. Nature. 2010;28:1045-8.

23. Martens JHA, Stunnenberg HG. BLUEPRINT: mapping human blood cell epigenomes. Haematologica. 2013;98:1487-9.

24. Zhang Y, Liu T, Meyer CA, Eeckhoute J, Johnson DS, Bernstein BE, et al. Model-based analysis of ChIP-Seq (MACS). Genome Biol. 2008;9.

25. Heinz S, Benner C, Spann N, Bertolino E, Lin YC, Laslo P, et al. Simple Combinations of Lineage-Determining Transcription Factors Prime cis-Regulatory Elements Required for Macrophage and B Cell Identities. Mol Cell. 2010;38:576-89.

26. Studd JB, Vijayakrishnan J, Yang M, Migliorini G, Paulsson K, Houlston RS. Genetic and regulatory mechanism of susceptibility to high-hyperdiploid acute lymphoblastic leukaemia at 10p21.2. Nat Commun. 2017;8:14616.

27. Bolger AM, Lohse M, Usadel B. Trimmomatic: a flexible trimmer for Illumina sequence data. Bioinformatics. 2014;30:2114-20.

28. Dobin A, Davis CA, Schlesinger F, Drenkow J, Zaleski C, Jha S, et al. STAR: ultrafast universal RNA-seq aligner. Bioinformatics. 2013;29:15-21.

29. Li B, Dewey CN. RSEM: accurate transcript quantification from RNA-Seq data with or without a reference genome. BMC Bioinform. 2011;12:323.

30. Robinson MD, McCarthy DJ, Smyth GK. edgeR: a Bioconductor package for differential expression analysis of digital gene expression data. Bioinformatics. 2010;26:139-40.

31. Love MI, Huber W, Anders S. Moderated estimation of fold change and dispersion for RNA-seq data with DESeq2. Genome Biol. 2014;15:550.

32. Lilljebjörn H, Henningsson R, Hyrenius-Wittsten A, Olsson L, Orsmark-Pietras C, von Palffy S, et al. Identification of ETV6RUNX1-like and DUX4-rearranged subtypes in paediatric B-cell precursor acute lymphoblastic leukaemia. Nat Commun. 2016;7:11790.

33. Qian M, Zhang H, Kham SK-Y, Liu S, Jiang C, Zhao X, et al. Whole-transcriptome sequencing identifies a distinct subtype of acute lymphoblastic leukemia with predominant genomic abnormalities of EP300 and CREBBP. Genome Res. 2017;27:185-95. Feb 1

34. Paulsson K, Lilljebjörn H, Biloglav A, Olsson L, Rissler M, Castor A, et al. The genomic landscape of high hyperdiploid childhood acute lymphoblastic leukemia. Nat Genet. 2015;47:672-7.

35. Paulsson K, Forestier E, Lilljebjörn H, Heldrup J, Behrendtz M, Young BD, et al. Genetic landscape of high hyperdiploid childhood acute lymphoblastic leukemia. Proc Natl Acad Sci USA. 2010;107:21719-24.

36. Ernst J, Kellis M. Chromatin-state discovery and genome annotation with ChromHMM. Nat Protoc. 2017;12:2478-92.

37. Becker PB. A user's guide to the Encyclopedia of DNA Elements (ENCODE). PLoS Biol. 2011;9:e1001046.

38. Grundberg E, Small KS, Hedman ÅK, Nica AC, Buil A, Keildson $S$, et al. Mapping cis- and trans-regulatory effects across multiple tissues in twins. Nat Genet. 2012;44:1084-9.

39. Westra HJ, Peters MJ, Esko T, Yaghootkar H, Schurmann C, Kettunen $\mathbf{J}$, et al. Systematic identification of trans eQTLs as putative drivers of known disease associations. Nat Genet. 2013;45:1238-43.

40. Ryoo H, Kong M, Kim Y, Lee C. Identification of functional nucleotide and haplotype variants in the promoter of the CEBPE gene. J Hum Genet. 2013;58:600-3.
41. Ward LD, Kellis M. HaploReg: a resource for exploring chromatin states, conservation, and regulatory motif alterations within sets of genetically linked variants. Nucleic Acids Res. 2012;40 (D1):D930-4.

42. Boyle AP, Hong EL, Hariharan M, Cheng Y, Schaub MA, Kasowski M, et al. Annotation of functional variation in personal genomes using RegulomeDB. Genome Res. 2012;22:1790-7.

43. Coetzee SG, Coetzee GA, Hazelett DJ. motifbreakR: an R/Bioconductor package for predicting variant effects at transcription factor binding sites: Fig. 1. Bioinformatics. 2015;31:btv470.

44. Fabregat A, Jupe S, Matthews L, Sidiropoulos K, Gillespie M, Garapati $\mathrm{P}$, et al. The reactome pathway knowledgebase. Nucleic Acids Res. 2018;46(D1):D649-55.

45. Mi H, Huang X, Muruganujan A, Tang H, Mills C, Kang D, et al. PANTHER version 11: expanded annotation data from Gene Ontology and Reactome pathways, and data analysis tool enhancements. Nucleic Acids Res. 2017;45(D1):D183-9.

46. Martin JS, Xu Z, Reiner AP, Mohlke KL, Sullivan P, Ren B, et al. HUGIn: Hi-C unifying genomic interrogator. Bioinformatics. 2017;33:3793-5.

47. Liu Y, Easton J, Shao Y, Maciaszek J, Wang Z, Wilkinson MR, et al. The genomic landscape of pediatric and young adult Tlineage acute lymphoblastic leukemia. Nat Genet. 2017;49:1211-8.

48. Schatz DG, Swanson PC. V(D)J recombination: mechanisms of initiation. Annu Rev Genet. 2011;45:167-202.

49. Wiemels JL, De Smith AJ, Xiao J, Lee ST, Muench MO, Fomin $\mathrm{ME}$, et al. A functional polymorphism in the CEBPE gene promoter influences acute lymphoblastic leukemia risk through interaction with the hematopoietic transcription factor Ikaros. Leukemia. 2016;30:1194-7.

50. Pope BD, Ryba T, Dileep V, Yue F, Wu W, Denas O, et al. Topologically associating domains are stable units of replicationtiming regulation. Nature. 2014;515:402-5.

51. Song C, Gowda C, Pan X, Ding Y, Tong Y, Tan BH, et al. Targeting casein kinase II restores Ikaros tumor suppressor activity and demonstrates therapeutic efficacy in high-risk leukemia. Blood. 2015;126:1813-22.

52. Schjerven H, Ayongaba EF, Aghajanirefah A, McLaughlin J, Cheng D, Geng H, et al. Genetic analysis of Ikaros target genes and tumor suppressor function in BCR-ABL1+ pre-B ALL. J Exp Med. 2017;214:20160049.

53. Novershtern N, Subramanian A, Lawton LN, Mak RH, Haining WN, McConkey ME, et al. Densely interconnected transcriptional circuits control cell states in human hematopoiesis. Cell. 2011;144:296-309.

54. Gombart AF, Shiohara M, Kwok SH, Agematsu K, Komiyama A, Phillip Koeffler H. Neutrophil-specific granule deficiency: homozygous recessive inheritance of a frameshift mutation in the gene encoding transcription factor CCAAT/enhancer binding protein- $\varepsilon$. Blood. 2001;97:2561-7.

55. Yamanaka R, Barlow C, Lekstrom-Himes J, Castilla LH, Liu PP, Eckhaus M, et al. Impaired granulopoiesis, myelodysplasia, and early lethality in CCAAT/enhancer binding protein epsilondeficient mice. Proc Natl Acad Sci USA. 1997;94: 13187-92.

56. Corfe SA, Paige CJ. The many roles of IL-7 in B cell development; Mediator of survival, proliferation and differentiation. Semin Immunol. 2012;24:198-208.

57. Benito JM, Godfrey L, Kojima K, Hogdal L, Wunderlich M, Geng $\mathrm{H}$, et al. MLL-Rearranged Acute Lymphoblastic Leukemias Activate BCL-2 through H3K79 Methylation and Are Sensitive to the BCL-2-Specific Antagonist ABT-199. Cell Rep. 2015;13 (12):2715-27.

58. French D, Yang W, Cheng C, Raimondi SC, Mullighan CG, Downing JR, et al. Acquired variation outweighs inherited 
variation in whole genome analysis of methotrexate polyglutamate accumulation in leukemia. Blood. 2009;113:4512-20.

59. Oehler VG, Guthrie KA, Cummings CL, Sabo K, Wood BL, Gooley $\mathrm{T}$, et al. The preferentially expressed antigen in melanoma (PRAME) inhibits myeloid differentiation in normal hematopoietic and leukemic progenitor cells. Blood. 2009;114:3299-308.

60. Parrish YK, Baez I, Milford T-A, Benitez A, Galloway N, Rogerio JW, et al. IL-7 dependence in human B lymphopoiesis increases during progression of ontogeny from cord blood to bone marrow. J Immunol. 2009;182:4255-66.

61. Peschon JJ, Morrissey PJ, Grabstein KH, Ramsdell FJ, Maraskovsky E, Gliniak BC, et al. Early lymphocyte expansion is severely impaired in interleukin 7 receptor-deficient mice. J Exp Med. 1994;180:1955-60.

62. Rich BE, Campos-Torres J, Tepper RI, Moreadith RW, Leder P. Cutaneous lymphoproliferation and lymphomas in interleukin 7 transgenic mice. J Exp Med. 1993;177:305-16.

63. Gala JL, Vermylen C, Cornu G, Ferrant A, Michaux JL, Philippe $\mathrm{M}$, et al. High expression of bcl-2 is the rule in acute lymphoblastic leukemia, except in Burkitt subtype at presentation, and is not correlated with the prognosis. Ann Hematol. 1994; 69:17-24.
64. Klobusická M, Kusenda J, Babusíkova O. Expression of p53 and bcl-2 proteins in acute leukemias: an immunocytochemical study. Neoplasma. 2001;48:489-95.

65. Ruvolo PP, Deng X, Carr BK, May WS. A functional role for mitochondrial protein kinase Calpha in $\mathrm{Bcl} 2$ phosphorylation and suppression of apoptosis. J Biol Chem. 1998;273:25436-42.

66. Ruvolo VR, Kurinna SM, Karanjeet KB, Schuster TF, Martelli AM, McCubrey JA, et al. PKR regulates B56 $\alpha$-mediated BCL2 phosphatase activity in acute lymphoblastic leukemia-derived REH cells. J Biol Chem. 2008;283:35474-85.

67. Diaz-Flores E, Comeaux EQ, Kim K, Beckman K, Davis KL, Wu $\mathrm{K}$, et al. BCL-2, a therapeutic target for high risk hypodiploid B-cell acute lymphoblastic leukemia. Blood. 2016;128:280 LP-280.

68. Paydas S, Tanriverdi K, Yavuz S, Disel U, Baslamisli F, Burgut R. PRAME mRNA levels in cases with acute leukemia: clinical importance and future prospects. Am J Hematol. 2005;79: 257-61.

69. Epping MT, Wang L, Edel MJ, Carlée L, Hernandez M, Bernards $\mathrm{R}$. The human tumor antigen PRAME is a dominant repressor of retinoic acid receptor signaling. Cell. 2005;122:835-47. 